\title{
A RECONFIGURAÇÃO DO PODER E A GOVERNANÇA GLOBAL COM E SEM GOVERNO: UM OLHAR SOBRE OS NOVOS ATORES
}

\section{THE POWER RECONFIGURATION AND GLOBAL GOVERNANCE WITH AND WITHOUT GOVERNMENT: A VIEW ON THE NEW ACTORS}

\author{
${ }^{1}$ Giovanni Olsson \\ ${ }^{2}$ Eduardo Baldissera Carvalho Salles
}

\section{RESUMO}

O presente artigo tem por objetivo abordar a reconfiguração do exercício do poder e da governança pelos novos atores internacionais. Inicialmente, identifica-se o poder tanto em relações conflituais quanto em consensuais, apresentando-o com uma categorização bifronte: poder sobre e poder para. Ainda, trata-se da mudança conceitual que envolve a governança, evidenciando que a autoridade pode ser exercida independentemente da vontade dos Estados, apresentando-a como governança com e sem governo. Por fim, mostra-se que os novos atores, especialmente as organizações não-governamentais e as empresas transnacionais, exercem papel relevante no cenário político da sociedade internacional contemporânea, cujas fronteiras nacionais tem a cada dia perdido a importância.

Palavras-chave: Poder, Governança Global, Relações Internacionais

\begin{abstract}
This article aims to address the reconfiguration of the exercise of power and governance by new international actors. Initially, the power is identified in both conflictual relations as in consensual, presenting him with a bifronte categorization: power on and power to. Still, it is the conceptual shift that involves governance, showing that the authority may be exercised independently of the will of States, presenting it as governance with and without government. Finally, it is shown that the new players, especially non-governmental organizations and transnational corporations exert significant role in the political landscape of contemporary international society, whose national borders have every day lost importance.
\end{abstract}

Keywords: Power, Global Governance, International Relations

\footnotetext{
${ }^{1}$ Possui Universidade Federal de Santa Catarina, UFSC - SC (Brasil). É professor Permanente do Programa de Mestrado em Direito da Universidade Comunitária Regional UNO-SC, (Brasil).

E-mail: gio.olsson@desbrava.com.br

${ }^{2}$ Mestrando em Direito pela Universidade Comunitária da Região de Chapecó, UNOCHAPECO - SC, (Brasil). E-mail: eduardo@carvalhosalles.com.br
} 


\section{INTRODUÇÃO}

O poder é um conceito de difícil delimitação. Ao tempo em que muitos pesquisadores já dissertaram a respeito, poucos foram os que chegaram aos problemas nevrálgicos dessa categoria conceitual. Há poder em todas as relações sociais? Pode o poder ser consensual? Há poder na estrutura social? Como arregimenta-se contemporaneamente?

Tais incógnitas são de relevante pertinência ao Direito e às Relações Internacionais na medida em que sua elucidação auxiliaria na compreensão do cenário político global. Será que o capitalismo, por exemplo, exerce poder sem que os sujeitos percebam sua interferência relacional? Os valores de tal sistema constituem poder?

Tais indagações, porém, acabam sendo retóricas: os juristas há muito concluem que a tutela de alguns bens é diuturnamente impedida pela estrutura econômica e social, sendo os direitos humanos o exemplo que mais nos salta aos olhos: enquanto o discurso protege, a práxis viola.

Os valores sociais comumente imprimem preconceito imperceptível ao sistema, e, embora constituam poder, seus efeitos simbólicos passam despercebidos pelos espectadores.

Aliado a isto, o declínio dos atores internacionais tradicionais tem se mostrado implacável. Os até então detentores da hegemonia global, União Europeia e Estados Unidos da América, por exemplo, permanecem em queda livre no jogo do poder, sendo o papel por eles antes desempenhado progressivamente usurpado por novos personagens. Entender por que o monopólio do poder estrutural tem escorrido das mãos de seus detentores históricos, bem como quem são os novos astros da dialética política internacional, têm sido algumas das indagações que movem nossas pesquisas.

Nesse contexto, o primeiro ponto a ser abordado trata da formação de uma categoria conceitual do poder, fenômeno complexo que acompanha a humanidade e suas instituições desde os primórdios. A compreensão desse elemento das relações sociais em termos amplos, com base nas novas categorias de "poder para" e "poder sobre", é essencial para bem caracterizar os papéis protagonizados pelos atores políticos na seara internacional.

O segundo ponto objetiva entender o fenômeno da governança global e sua concorrente conformação com e sem governo. O descolamento das categorias de governo e governança, até então monolíticas, gera a curiosa introdução da possibilidade de governança sem governo. Os contornos dessa nova realidade devem ser explorados, porque ela se veicula por novos atores no seu protagonismo. 
O terceiro e derradeiro, por conseguinte, é exatamente a investigação dos novos atores nesse contexto de governança sem governo, particularmente as corporações transnacionais e as organizações internacionais não-governamentais, com seus limites e possibilidades. O deslocamento da governança para fora do âmbito dos governos e, pois, dos atores estatais clássicos, constitui uma nova e desafiadora realidade para a sociedade contemporânea globalizada.

\section{A RECONFIGURAÇÃO DO PODER: PODER SOBRE E PODER PARA}

A investigação do poder político exige, preliminarmente, a elaboração de um conceito que seja capaz de explicar, ao mesmo tempo, a acepção genérica do poder com as peculiaridades inerentes ao jogo da política. Carece, portanto, de um ponto de vista que englobe tanto o poder tradicional, quanto aquele construído através das lentes contemporâneas da teoria política.

Tal desiderato pode ser atingido pela combinação de duas formulações intercomplementares. A primeira, aliada à concepção clássica do poder, respalda-se nos teóricos sociais e políticos da modernidade, como Thomas Hobbes (1957, p 64) e Max Weber (1980, p. 28), cujos escritos narram um poder eminentemente intransitivo, que age "sobre" os corpos e mentes. A segunda, intenta integrar à primeira a compreensão de que o poder não apenas oprime e submete, mas também pode ser fruto do diálogo, e, assim, cooperar "para" transformar, na linha de Michel Foucault (1980, p. 72) e Pierre Bourdieu (1991, p. 166).

Entendendo que a concepção hodierna do poder deve conciliar ambas as linhas de pensamento, estrutura-se a investigação sob um novo prisma referencial, razão pela qual desenvolve-se o estudo a partir das categorias de "poder sobre" e "poder para".

Embora o poder como fenômeno acompanhe a sociedade humana desde os seus primórdios, e integre as relações interpessoais sob uma modalidade ou outra, a introdução dessa terminologia constitui uma novidade recente. A primeira abordagem que adota essa terminologia está em Hanna Fenichel Pitkin, ao asseverar que “[s]e 'poder' fosse uma etiqueta para certos fenômenos, tal distinção não poderia ser de grande importância, uma vez que as duas expressões necessariamente envolveriam a mesma idéia de poder simplesmente postas em diferentes contextos verbais". Segundo ela, a pessoa pode exercer poder sobre outro ou outros, de maneira relacional, sem que haja um relacionamento, ao tempo em que pode ter poder para fazer ou realizar alguma coisa ela própria, mas que envolvam outras pessoas, como em uma 
ação social ou política, de modo que "a ideia de poder em 'poder para' pode ser significativamente diferente da ideia de poder em "poder sobre"” (1972, p. 276-277).

A introdução dessas categorias constitui uma autêntica revolução epistemológica no estudo do poder, porque a abordagem de Pitkin permitiu ver com clareza que não se trata de dois fenômenos distintos, mas sim o mesmo, em duas feições diversas, ou, em outras palavras, duas espécies do mesmo gênero. Na teoria política moderna, de forte influência weberiana, poder era compreendido apenas como um estado ou possibilidade de sujeição, opressão ou violência, e não se reconhecia que o consenso, o diálogo e a produção de uma nova realidade pudessem ser uma espécie daquele mesmo gênero. Mais do que um mero instrumento de exercício da dominação do homem pelo homem, o poder também constrói e opera transitivamente em via de mão dupla, como se observa, por exemplo, na democracia participativa.

No mesmo sentido, Haugaard (1997, p. 137-141) nota que as relações de poder são formadas por conflitos e consensos, cujas razões e posições dos atores são cambiantes, restando ora expressas e ora tácitas. Dyrberg (1997, p. 251), a seu turno, assinala que tais categorias são inter-relacionadas, sendo a primeira responsável pela "restrição à vontade", enquanto que à segunda incumbe a "formação de vontade". O seu aporte teórico, na mesma direção de Pitkin, mas por outros fundamentos, permite reconhecer que o poder pode ser, no primeiro caso, preponderantemente conflitual, e, no segundo, consensual.

O "poder sobre", portanto, relaciona-se à sujeição de um ator sobre outro. É o que ocorre, por exemplo, no âmbito político-jurídico da nação, cujo Estado, por deter o monopólio da violência legítimo, exerce poder sobre as pessoas a fim de impor a normalização das condutas. Justamente por isso, o Direito tornou-se o mais importante aparelho de regulação social da modernidade: ele legitima e restringe o exercício do "poder sobre", mecanizando o seu exercício por meio de instrumentos como a tripartição dos poderes, o devido processo legal, o direito de defesa, e outros tantos. Isso vale para a tributação e para a persecução penal, por exemplo. Da mesma forma, no âmbito internacional, atores de maior envergadura econômica ou militar, com mais "ouro e tanques", fazem prevalecer a sua vontade.

Max Weber, apontado como um dos grandes teóricos do poder, é um grande representante desta escola empírica do pensamento, porque define o poder como instrumento de dominação, ou seja, um mecanismo vertical e conflitual que gera "poder sobre" algo. Segundo ele, o poder é "a possibilidade, dentro de um relacionamento social, de realizar a 
vontade de alguém mesmo contra a resistência, independentemente da base na qual essa possibilidade se funda" (WEBER, 1980, p. 28). Assim, seu argumento é de que o poder não se traduz em violência, mas em "possibilidade de", podendo ser simbólico ou imaterial (BOURDIEU, 1991, p. 164), bem como dissimulado ou difuso (FOUCAULT, 1980, p. 119). Weber também elenca a resistência como elemento capital do poder, porque pressupõe que, quando um ator sujeita-se à vontade de outro, o conflito torna-se latente. Por fim, suscita ele que o exercício de poder não carece de legitimidade. Pode ele respeitar a "racionalidade-legal", como na aplicação de sanções judiciais pelo Estado-nação, ou os pressupostos "carismáticos" ou "tradicionais", que se referem, por exemplo, à auto regulação empreendida por grandes personalidades ou pelas comunidades dominadas pelo tráfico de drogas ou o crime organizado.

Não por acaso, tais postulados encontraram eco no paradigma realista das relações internacionais. A predominância de temas como a "segurança" e o "equilíbrio do poder" nas obras de Morgenthau e Waltz é evidência irrefutável de que os internacionalistas compreendiam o mundo a partir de relações em que certos atores impunham suas vontades sobre os outros, especialmente com uso de predicados econômicos e militares.

Em que pese as assertivas de Weber continuarem a ecoar na academia, as transformações sociais contemporâneas incitam a adoção de um novo paradigma científico, especialmente porque a força militar detida pelos Estados pode ser menos significativa diante do poder econômico ou ideacional dos demais atores. Como já vêm advertindo os construtivistas sociais, ideias importam tanto ou mais que "ouro e tanques" na prática da sociedade internacional. Assim, tendo o Estado-nação sido eclipsado pelo fulgor dos novos atores, especialmente as corporações transnacionais $\mathrm{e}$ as organizações internacionais nãogovernamentais, o "poder sobre" tem seu espaço relativizado, justamente porque o Leviatã não mais detém "o monopólio da violência legítima”, compartilhando-a com autoridades privadas cujas interferências não conhecem fronteiras. Não se trata apenas de deslocamento do centro de gravidade do poder do campo militar para o econômico, mas, em paralelo, também para o campo ideacional, onde idéias e discursos são muito fortes na orientação de ações políticas. Isso constitui um novo horizonte a explorar.

A segunda tipologia, por sua vez, remonta suas origens na teoria aristotélica, para a qual o homem é um ser político por natureza (ARISTÓTELES, 1996, p. 12 e ss.). Tal abordagem permaneceu incompreendida em toda a sua extensão e em segundo plano até o século XX quando, principalmente nos escritos de Parsons e Arendt, sinalizou-se que o enfoque conflitual era incapaz de revelar toda a problemática do conceito. Para estes, o "poder não é 
dado ou inato, mas sim produzido ou construído pelo diálogo e consenso pela sociedade e, assim, o exercício do poder não conduz apenas a uma exclusão de atores ('jogos de soma zero')" (OLSSON, 2014, pp. 148-149).

Parsons elabora a conhecida analogia entre o poder e o dinheiro, apontando que o poder é socialmente construído por diálogo e consenso, "circulando" na sociedade tal qual o dinheiro (1967, p. 308 e ss.). Arendt vai mais longe, aduzindo que o poder não tem relacionamento de comando e obediência, mas precisa de apoio popular para perdurar nas instituições políticas. Nessa linha, a filósofa sequer admite a forma conflitual do poder, identificando-o como mera expressão da violência e da força física (ARENDT, 1970, pp. 40, $44)$.

Assim, o "poder para" manifesta-se nas relações de cooperação em que os atores agregam-se em concertação política, cujo produto constrói e liberta. Ou seja, sem que os partícipes sofram qualquer tipo de imposição ou prejuízo, edifica-se uma aspiração coletiva, no limite dos interesses individuais, cujo exemplo mais palpável é o orçamento participativo ou outras expressões da democracia participativa. Na seara internacional, a convergência de pretensões possibilita a criação de organizações não-governamentais, ou mesmo a constituição de organizações intergovernamentais, as quais produzem resultado político e institucional mais amplo do que o resultante da soma dos esforços individuais, sem que nenhum dos atores sofra prejuízos ou perdas no seu poder pessoal. A legitimação se dá pelo Direito, que pode estabelecer mecanismos de igualdade e oportunidade, bem como pela própria prática política. Portanto, e em contraponto ao "poder sobre", o "poder para" manifesta-se de dois ou mais atores em conjunto para um terceiro, que é o seu resultado, e não de um em desfavor do outro.

Embora diversos teóricos contemporâneos continuem a associar a política à subordinação e ao medo, esse novo entendimento da teoria do poder alia ambas as visões, propondo que o poder é um fenômeno complexo, que ao mesmo tempo pode ser opressor, impositivo e conflitual, e também pode ser libertário, produtivo e consensual, de acordo com sua conformação estrutural naquela relação interpessoal.

Essa compreensão bifronte do poder, em que os sentidos não se excluem, mas se complementam, é audaz na medida em que propõe a identificação de que o poder é um ingrediente permanente da vida social, constituindo atrevido método de compreensão do protagonismo dos atores na pós-modernidade, cujo tabuleiro é reconfigurado de forma cada vez mais dinâmica e complexa. 
Além da dicotomia conflito-consenso, identificam-se contribuições relevantes de diversos outros pensadores. Pierre Bourdieu e Michel Foucault, já antecipados, mas graças às peculiaridades de suas proposições, devem receber abordagem em separado.

A expressão material do poder é intuitivamente a nota que, dada a sua visibilidade, é usualmente levada a cabo pelos pesquisadores do fenômeno. Os conflitos bélicos, a violência empregada pelos mais fortes, e a sucumbência das economias do terceiro mundo frente ao imperialismo americano povoam o imaginário popular, que recheiam histórias com tragédias envolvendo armas, força e dinheiro. Entretanto, e além dessas, o poder possui expressões imateriais, nomeadamente "simbólicas", que são objeto de estudo específico de Bourdieu.

Para ele, o "poder simbólico" é "aquele poder invisível que pode ser exercido somente com a cumplicidade daqueles que não querem saber que eles são sujeitos a ele ou mesmo que eles próprios exercem ele" (BOURDIEU, 1991, p. 164). Ou seja, o poder não tem morada no sistema, mas deriva da relação entre os atores. Assim, irradia-se na estrutura social, comumente passando despercebido, porque, além de a legitimidade de seus atores ofuscar a sua presença, este poder é intencionalmente dissimulado.

Aliás, emana de sua inteligência a assertiva de que os meios de comunicação podem tornar-se instrumentos de dominação implícitos, porque o simbolismo oculta-se nos discursos, categorias, imagens, ideologias, e outros tantos fenômenos professados na sociedade. Exemplo deste dado é “a suposta 'verdade' emanada das fontes de informação dos serviços de 'inteligência' de um Estado, que podem (e mesmo puderam) justificar guerras, embora, logo a seguir, se verificasse que a crença na legitimidade dos interlocutores e a manipulação discursiva foram as únicas 'verdades' na realidade internacional” (OLSSON, 2014, p. 156).

Também se identifica que instituições seculares emanam poder, como quartéis e prisões, e, embora à primeira vista ignorados pelos pesquisadores, igualmente espaços sociais insuspeitos como escolas, famílias e hospitais. As armas e o dinheiro são "coisas" que, ao lado das "palavras" dos atores, também exercem poder e, a respeito destas, Foucault aprofundou sua análise.

Foucault contribui de maneira intensa ao tema, porque, além de identificar poder em pequenas coisas e espaços, constituindo a chamada "microfísica", relacionou-o com saber e discurso. Para ele, o poder não é apenas conflitual e opressivo, mas também edificador de novas coisas e idéias, tendo, portanto, um caráter predominantemente consensual e "positivo". Segundo ele, o poder é "uma rede produtiva que corre através de todo o corpo social, mas muito 
mais que uma instância negativa cuja função é repressão", presente em relações de toda natureza, como na família e nas escolas (FOUCAULT, 1980, p. 119).

Além disso, Foucault assinala que o poder não é hermético, se (retro)alimentando dos discursos. O poder, na sua leitura, constrói saberes e tipos discursivos, como o "louco" ou o “marginal”, por exemplo, de sorte que, por constranger e disciplinar as relações, o poder produz novas realidades sociais, o que dá substrato conceitual ao ditado de que "saber é poder".

Detalhadas as categorias "poder sobre" e "poder para" como conflitivas e consensuais, pode-se prosseguir objetivando entender as categorias de governo e governança e o seu processo de descolamento conceitual e sua relação com a autoridade.

\section{A GOVERNANÇA GLOBAL COM E SEM GOVERNO}

$\mathrm{Na}$ teoria política clássica, governo e governança sempre foram conceitos correlatos, como duas faces de uma mesma moeda. O conjunto de instituições com a estrutura de pessoal e material (governo) era quem exercia o poder político na consecução de atividades (governança). Não havia governo que não exercesse governança, e não havia governança que não fosse exercida por um governo.

Para esse efeito, era irrelevante se o governo fosse legítimo ou não, democrático ou não: por ser governo, naturalmente exercia algum tipo de governança, impactando na realidade social. James Rosenau já observava que ambos os conceitos, embora diferentes, estavam imbricados por uma circunstância em comum, que é o fato de serem "sistemas de regras" (ROSENAU, 2002, p. 72), voltadas para a estrutura (no governo) ou voltadas para a sua função social ou processo social (na governança).

Para o presente estudo, governo pode ser definido como "a entidade através da qual se busca ordem e são demarcados e implementados objetivos" (ROSENAU, 2002, p.72). Governança, por sua vez, e ainda seguindo o mesmo autor, é um conjunto de atividades orientadas à realização de objetivos políticos, independendo de haver, ou não, autoridades formais na sua promoção (ROSENAU, 2002, p. 71-2).

Mais do que isso, governo e governança, como conceitos da teoria política, eram categorias do espaço público, porque eram atributos apenas do Estado-nacional, o que se exercia internamente pelo princípio da supremacia. O Leviatã hobbesiano, como modelo políticojurídico da modernidade, era o protagonista público por excelência, que, por isso, detinha o monopólio da violência legítima weberiana. Por projeção da autoridade estatal externamente 
soberana, poderia ser atribuído a entes públicos derivados, como organizações internacionais intergovernamentais, mas, com isso, não perdia sua natureza de ação política necessariamente pública e condicionada por um pressuposto interesse público.

Dentro da mesma lógica, o Estado-nacional possuia um chefe de Estado que podia ou não coincidir com o chefe de Governo, que, por sua vez, era quem encabeçava a estrutura de governança, replicada internamente em entes regionais ou federados e municipais ou locais.

Entretanto, essa realidade mudou extraordinariamente na sociedade contemporânea.

Uma primeira novidade, cabe notar, foi a extensão do conceito de governo e governança para entes privados, no âmbito da administração empresarial. Desde meado do século XX, difunde-se a idéia de "governo de empresa" e de governança "privada" ou "corporativa", com a apropriação da idéia geral de conjunto de atividades orientadas, mas redefinida para fins econômicos, notadamente na promoção de faturamento e de lucros. Essa primeira transformação projetou-se profundamente nas corporações transnacionais, por exemplo, em que esses termos são largamente difundidos. Mas o que realmente interessa neste momento é uma segunda novidade.

O aspecto mais notável dessa mudança conceitual foi, em si mesmo, o descolamento de governança do núcleo da idéia de governo na própria teoria política, de tal forma que passam a ser concebidos sem necessária coincidência um com o outro. Essa transformação foi um processo lento, mas, combinada com a anterior, permite reconhecer que, mesmo dentro do espaço público, há governo sem governança, e governança de questões públicas sem governo. Por isso, pode-se falar em governança com governo e governança sem governo.

Essa concepção, entretanto, que abala os postulados da teoria política clássica, é cada vez mais evidenciada na sociedade contemporânea.

No âmbito interno dos Estados, é desnecessário insistir nos incontáveis exemplos de parcelas territoriais que estão fora do controle de fato das políticas públicas dos governos nacionais, seja por conta de exclusão social intensa, seja mesmo pelo controle de milícias ou do crime organizado, por exemplo. Nessas situações, existe não por acaso também um evidente pluralismo ou policentricidade jurídicos, em que se identificam fontes paralelas de normatização social que não são emanadas do Estado e tampouco efetivadas por ele, como o "direito do morro" ou de "Pasárgada" (SANTOS, 2014, p. 30). Embora esses exemplos possam ser tomados como exceções, e apenas confirmem a regra de que a governança com governo seria ainda preponderante no âmbito nacional, situação muito diversa ocorre no nível supranacional.

Na sociedade internacional globalizada, como se disse, o panorama é bem distinto. Há uma problemática intensa de governança no nível global por pelo menos duas razões. 
A primeira delas é a de que não existe uma entidade política supranacional com autoridade legítima e efetiva no planejamento, implementação e execução de políticas públicas em escala global. A Organização das Nações Unidas, como se sabe, que poderia ser a entidade de maior projeção, padece de limitações institucionais e estruturais sérias, ainda vinculada a um desenho geopolítico do fim da década de 1940.

Essa circunstância, por certo, está conectada diretamente com outra: a ausência de regulação jurídica internacional dotada de sanção e efetividade globais. O Direito Internacional Público, apesar de sua pretensão de normatividade acima dos Estados, é desprovido de sanções, salvo morais, ou, ainda que sejam materiais, bastante limitadas, pontuais e dependentes de acordos bem circunstanciais. Nesse particular, cabe observar que o Direito Internacional Público parece não ter conseguido superar o paradigma estatal e a regra de soberania, ignorando que, além de Estados-nação e suas organizações internacionais intergovernamentais derivadas, há novos atores no cenário global que escapam de seu controle ostensivamente. Se o Direito Internacional é inefetivo porque não há ente governativo global, ou se não há este porque aquele é incapaz de regular as condutas dos atores, é um outro debate, mas é evidente que, a despeito da relação de causa e efeito entre as dimensões política e jurídica, não há governança com governo no nível global. Se os mais de 200 Estados nacionais fossem comparados com "cidadãos" de uma hipotética sociedade "entre nações", poder-se-ia dizer que inexiste um Leviatã dos Leviatãs nessa mesma sociedade agora globalizada.

A segunda razão é a de que, além do já mencionado, há uma clara desagregação de autoridade do próprio Estado nacional (ROSENAU, 2002, p. 71), que seria o exemplo mais completo de governança com governo na teoria política clássica. Esse ente hobbesiano não possui condições de exercer governança para além de seu território, e, mesmo dentro dele, suas limitações são progressivamente cada vez mais evidentes na implementação de ações de interesse público.

Há uma série de questões para as quais o Estado isoladamente não consegue apresentar respostas, seja porque são interdependentes de outros atores, seja porque exigem recursos além da sua capacidade, por exemplo (KOENIG-ARCHIBUGI, 2002, p. 47). Alguns casos são o aquecimento global, a escassez de água potável ou a regulação de capitais especulativos globais. Em qualquer um desses exemplos, e embora intuitivamente os Estados busquem acordos para atuação coletiva com outros Estados, a celebração desses instrumentos do Direito Internacional não garante o êxito da governança, seja porque nem todos os envolvidos são obrigados a participar, ou seja porque os participantes podem não se sentir suficientemente motivados a 
implementar essas políticas, diante da ponderação dos custos e benefícios para sua realidade interna nacional. Sempre haverá, como exemplos, um poluidor que não quer arcar com os custos econômicos e sociais de medidas industriais restritivas ou com a perda de recursos especulativos para outros mercados. Ainda que sejam vítimas de problemas globais comuns, os Estados também são concorrentes entre si em tantas outras questões e não necessariamente cooperativos em medidas que impactem as vidas de seus nacionais.

O mesmo se pode dizer dos espaços globais extraterritoriais, como a Antártida, o espaço sideral e as águas internacionais. Ainda que diversos "regimes internacionais" pretendam regulá-los, a abrangência, a legitimidade e a efetividade desses sistemas de regras são questões no mínimo problemáticas.

A compreensão mais abrangente dessa transformação nas categorias de governo e governança, por sua vez, não seria completa sem o resgate da categoria da autoridade.

O estudo do poder não pode prescindir da análise da autoridade, que é entendida como uma forma institucionalizada de poder (HALL; BIERSTECKER, 2002, p. 4). Esse conceito operacional é fundamental porque a institucionalização do poder opera-se tanto no espaço público como no privado, na medida em que pressupõe o poder por parte do agente (econômico, militar, etc.) e o reconhecimento por parte dos destinatários desse mesmo poder (sujeitando-se e obedecendo). Nesse sentido, as ditas “esferas de autoridade" (ROSENAU, 2002, p. 72) podem ser construídas por processos públicos democráticos (eleições, investidura em cargos por concurso, separação e limitação de poderes e outros mecanismos) ou mesmo por mecanismos privados (eleição de diretorias por acionistas ou contratação para cargo de gestão empresarial, por exemplo).

Em qualquer dos casos, note-se, essa esfera de autoridade (pública ou privada) pode ser lícita ou mesmo ilícita, dependendo da conformidade com o sistema jurídico em cada caso: no espaço público, um golpe de Estado investe o novo governante em uma esfera de autoridade (ilícita), assim como, no espaço privado, uma máfia poderosa investe o chefe da sua quadrilha também em uma esfera de autoridade (ilícita). Em ambos os casos, há poder dos investidos e reconhecimento dos destinatários que atendem às suas ordens, por medo, interesse ou qualquer outro motivo. Ambos são autoridades, e, claro, exercem poder.

Essa transformação conceitual é muito importante para compreender o papel dos novos atores globais, particularmente corporações transnacionais e organizações não-governamentais e mesmo grupos terroristas ou movimentos sociais globais. Em qualquer desses casos, há grande poder envolvido, que pode ser econômico no caso daquelas, mas também moral ou mesmo 
militar. Além disso, e em todos eles, há autoridade privada tipicamente, ao oposto da tradicional autoridade pública do Estado-nação. Não por acaso, fala-se em autoridade privada "de mercado", "moral" e tantas outras, atuantes e poderosas enquanto não desafiadas por outros atores (HALL; BIERSTECKER, 2002, p. 5), e, por serem autoridades privadas, exercem governança sem governo.

Note-se, ainda de passagem, que a autoridade militar de um Estado (ou grupo terrorista, eventualmente) e a autoridade de mercado de uma corporação transnacional expressam poderes que são materialmente tangíveis, por repousarem no "ouro e tanques" de que um e outro dispõe, e ainda podem ser explicados dentro de modelos epistemológicos tradicionais das Relações Internacionais. Entretanto, e quando se fala da autoridade moral de uma organização internacional não-governamental ou de um movimento social global, por exemplo, que possui extraordinário reconhecimento e poder pela especialidade técnica e capacidade de articulação em temas definidos (meio-ambiente, proteção das baleias, etc.), está se rompendo um paradigma realista ou mesmo interdependentista, porque a base do seu poder é intangível. Nesse último caso, apenas o aporte de um acervo teórico do construtivismo social consegue explicar a nova realidade, ao reconhecerem que ideias podem valer mais do que ouro e tanques em certos contextos globais (RUGGIE, 1998, p. 133).

Em síntese, e diante dessa realidade contemporânea extremamente desafiadora, há inúmeras situações em que os governos, de qualquer nível, não conseguem exercer governança, e, assim, diversas questões de interesse coletivo global compartilhado permanecem precaria e/ou inefetivamente reguladas. Em outras palavras, e retomando o argumento inicial, não há governo em condições de exercer governança sobre elas, pelo menos não no paradigma tradicional da teoria política ainda marcadamente estatocêntrico.

Em seguimento, e para tentar melhor compreender essas atuais problemáticas da sociedade internacional contemporânea, deve-se avançar para o estudo dos novos atores globais que protagonizam nesse cenário. Dentre eles, merecem destacada ênfase as corporações transnacionais.

\section{O PAPEL DOS NOVOS ATORES}


O ator atua, interpreta e desempenha papel previamente definido. Por isso, o termo foi apropriado pelas Relações Internacionais para designar os agentes que influenciam e interagem na sociedade internacional em situações de poder conflitual ou consensual.

Algumas características são importantes para definir os atores, como, por exemplo, a capacidade deles em executarem papéis e desígnios definidos pelo sistema internacional, os quais comumente englobam temas econômicos, militares, políticos, sociais e religiosos.

No entanto, nem toda função desempenhada pelos atores surtirá o mesmo efeito, porque o cenário sofre variações conforme a autonomia, habilidade e capacidade de influência do intérprete. Essas variações são elementares para o conceito de ator internacional, uma vez que, segundo Esther Barbé, este "é aquela unidade do sistema internacional (entidade, grupo, indivíduo) que tem habilidade para mobilizar recursos que lhe permitem alcançar seus objetivos e capacidade para exercer influência sobre outros atores do sistema e que goza de certa autonomia" (BARBÉ, 1993, p. 117).

Os fatores determinantes do protagonismo dos atores são categorizados por Odete Maria de Oliveira em cinco itens: geográfico, demográfico, econômico, militar e de segurança e tecnológico (OLIVEIRA, 2014, p. 68-96). Tais fatores interferem no desempenho dos atores internacionais, condicionando o agir, de modo que, dependendo dos interesses dos envolvidos, o cenário pode resultar povoado com diversos métodos de operação. Oliveira ainda relata que “esses tão diversificados atores, por sua vez, com funções as mais diferenciadas, transitam em diferentes cenários, criando suas próprias condições de forças emergentes, confrontando e até rompendo com o monopólio de decisão do Estado (...)” (OLIVEIRA, 2014, p. 109).

Como reflexo da complexidade do tema, diversas classificações são utilizadas por pesquisadores nacionais e estrangeiros, sendo que a aludida autora desmistifica a questão, sinalizando a confluência dos atores em três categorias generalistas, apresentando um "parâmetro eclético" que, observando a amplitude dos fluxos encetados pelo desenvolvimento da tecnologia da informação, engloba "os denominados atores tradicionais, os novos atores e os atores emergentes" (OLIVEIRA, 2014, p. 100).

No que tange à referida categorização, os atores tradicionais são os Estados nacionais e as organizações internacionais intergovernamentais, porque estas são derivações inexoráveis da vontade estatal. Os novos atores são as organizações internacionais não-governamentais e as empresas transnacionais, cuja principal característica é a capacidade de influência de grande 
parte da população mundial, porquanto dispõem de recursos materiais e ideacionais capazes de sujeitar os demais atores. Por fim, os atores emergentes são fluídos e voláteis, localizando-se em áreas de grande prospecção, como os movimentos sociais, os partidos políticos, sindicatos, mídia, crime organizado, terrorismo, entre outros. Em razão da vivacidade das relações, não é possível exaurir sua abrangência, situação esta que, ao contrário de limitar o campo de atuação, é o combustível que projeta tais atores no cenário internacional.

Os novos atores, portanto, possuem como marco distintivo o fato de serem constituídos com certa institucionalidade e burocracia, cujo comando é exercido exclusivamente por agentes privados. Assim, como a presente investigação se propõe a revelar o impacto desses novos atores, o exercício de governança será trabalhado somente em sua face sem governo.

No âmbito desses novos atores, há pelo menos duas espécies que merecem especial atenção: as organizações internacionais não-governamentais e as empresas transnacionais.

As organizações internacionais não-governamentais são entes internacionais que funcionam independentemente dos atores públicos, não têm fins lucrativos, possuem baixo nível de burocracia e desempenham ações orientadas a desígnios específicos. Comumente, orientam-se em pautas de interesse global, como por exemplo a promoção dos direitos humanos, da saúde e da paz, e o combate à corrupção e à miséria. Desse modo, pode-se afirmar que a multiplicidade de desígnios e métodos de atuação é o ponto nodal do fenômeno, porque a plasticidade de seus feitos permite a consolidação da importância no cenário global.

Tais organizações não precisam da coisa pública para legitimação de seu exercício de poder, porque este se dá em razão da autoridade moral ou privada, eminentemente discursiva e de natureza não-econômica exercida sobre a sociedade civil, cujos atributos de diferenciação mais relevantes são a independência, a confiabilidade, a representatividade e a responsabilidade.

Por outro lado, as empresas transnacionais têm emergido na sociedade global contemporânea como atores destacados, porque, detentoras de grande poder econômico, exercem governança para muito além das fronteiras de seus Estados nacionais.

Reflexo da globalização neoliberal, que aparelhou a racionalidade econômica com ferramentas telecomunicativas e de informática, as empresas transnacionais atuam com uma interligação complexa entre mercado, produção e gestão dos negócios. Com capital e direção apátridas, e ramificadas por todo o globo, várias delas possuem faturamento anual superior à soma do produto interno bruto de dezenas de países somados.

O poder dessas corporações, a seu turno, não se relaciona com o exercício de autoridade pública, mas com uma autoridade de mercado, caracteristicamente privada e econômica. 
Ademais, a economia incide preponderantemente nas relações que as envolvem, uma vez que, além de viabilizar a mobilização de recursos em curtos espaços de tempo, permite a elisão seletiva de marcos regulatórios estatais, concertando sistemas jurídicos de diversas nações.

A governança exercida pelas empresas transnacionais é exclusivamente sem governo, costumando ser unidirecional de baixo para cima, por governança de mercado, ou seja, guiada pelo desiderato principal de obtenção de lucro. Contudo, também se identificam situações de governança unidirecional de cima para baixo, como, por exemplo, quando estas exigem dos Estados a concessão de benefícios tributários ou infraestruturais para a instalação de parques fabris, e a posição do ente estatal é de sujeição política diante do peso econômico do outro ator e sua importância para a economia nacional. Por fim, observa-se o exercício de poder multidirecional, articulado com outros partícipes do cenário internacional, como, por exemplo, quando tais atores dispensam recursos e logística para, de maneira articulada, combater catástrofes naturais.

A governança econômica das empresas transnacionais escapa ao controle dos Estados nacionais, porque o colossal poder de movimentação comercial e financeira, e as repercussões que estas geram nos índices de emprego, renda e meio ambiente, fazem com que o exercício de governança independa da legitimidade internacionalmente construída ou da existência de responsabilidade pelos efeitos de seus atos.

Nota-se, assim, que o exercício do poder global, desprovido de governo, mas apinhado de governanças, assemelha-se com o modelo medieval (FRIEDRICHS, 2001, p. 483-91), porque atores sociais, econômicos e políticos estariam competindo e cooperando num tabuleiro sem supremacia autoevidente. Nesse contexto, os atores prestam servidão a diversos senhores sobrepostos, dos mais variados ramos societais, configurando um "novo medievalismo". Ainda que tal analogia histórica não possa ser ratificada sem alguma controversa, ela é didática para ressaltar a reestruturação do exercício de poder no cenário internacional, em que o Estado é agora somente um dos múltiplos atores exercentes de poder global.

A observação desse fenômeno leva à percepção de que o espaço público global transformou-se em um cenário protagonizado por uma miríade de atores com interesses múltiplos, ora convergentes, contraditórios ou concorrentes, que se interrelacionam e reciprocamente se condicionam. Trata-se de "uma arena institucionalizada de discurso, contestação e ação organizada em torno da produção de bens públicos globais” (RUGGIE, 2004, p. 519). 
E, ainda que estas ponderações sejam incompletas e fragmentadas, é incontroverso que o exercício de poder no cenário político internacional passou (e passa) por uma reorganização do secular e monolítico "sistema de Estados". As relações agora tendem a ocorrer além dos limites estatais, em dimensões que desconhecem os parâmetros nacionais, tal como as redes eletrônicas, de onde se extrai uma crescente produção de normas privadas que objetivam regular as interações entre os diversos atores transnacionais.

\section{CONSIDERAÇÕES FINAIS}

O presente trabalho dedicou-se a inicialmente elaborar uma construção conceitual do poder, adotando a categorização "poder para" e "poder sobre", cuja perspectiva assinala a existência de poder tanto na formação de consenso quanto de conflitos. Verificaram-se efeitos de dominação e autoridade não só em relações verticais weberianas, mas também nas de cooperação e construção eminentemente horizontais.

Após, apurou-se que o exercício de governança não mais depende da existência de um governo formalmente estabelecido, porque o poder dispensa a presença de uma autoridade racional-burocrática, sendo cada vez mais notável que novos atores exercem poder e influência.

Importante salientar, ainda, que historicamente os atores estatais desempenharam papéis de maior evidência no cenário internacional, mas, com o advento da globalização, diferentes e novos personagens começaram a partilhar os holofotes da política global. Dentre estes novos atores, destacam-se as organizações não-governamentais, cuja quantidade e disparidade de objetivos está crescente, bem como as empresas transnacionais, cujo gigantesco poder econômico e faturamento são capazes de sujeitar as decisões políticas dos Estados.

Este cenário quase medieval, cuja governança é exercida por um leque de atores em concorrência de lealdades, faz com que observemos que o espaço global tem abalado os limites das fronteiras estatais reais ou imaginárias profundamente. Nesse sentido, o protagonismo de atores variados, com interesses convergentes, contraditórios ou concorrentes, de dimensões e atributos muito distintos, desde a economia às redes tecnológicas, é um fato que não pode ser mais ignorado e merece um olhar cada vez mais atento.

\section{REFERÊNCIAS}


ARENDT, Hannah. Crises da república. Tradução de José Volkmann. 2a ed. São Paulo: Perspectiva, 2006.

ARENDT, Hannah. On violence. New York: Harcourt, Brace \& World, 1970. 106p.

ARISTÓTELES. The Politics and the Constitution of Athens. Edited by Stephen Everson. Revised student edition. Cambridge: Cambridge University Press, 1996.

BOURDIEU, Pierre. Language and symbolic power. Edited and introduced by John B. Thompson. Translated by Gino Raymond and Matthew Adamson. Oxford: Polity Press, 1991, $302 \mathrm{p}$.

DYRBERG, Torben Bech. The circular structure of power: politics, identity, community. London: Verso, 1997. 292p.

FOUCAULT, Michel. Microfísica do poder. Tradução de Roberto Machado. 14 ed. Rio de Janeiro: Graal, 1979, 295 p.

FOUCAULT, Michel. Power and Knowledge: selected interviews and other writings 19721977. Edited by Colin Gordon. Transl. by Colin Gordon et al. New York: Pantheon, 1980.

FOUCAULT, Michel. Two Lectures. In: KELLY, Michael (Ed.). Critique and Power: recasting the Foucault/Habermas debate. Cambridge: The MIT Press, 1994. p. 12-58.

FRIEDRICHS, Jorg. The meaning of new medivalism. European Journal of International Relations, London, v. 7, p. 475-502, 2001.

HALL, Rodney Bruce; BIERSTECKER, Thomas J. The emergence of private authority in international system. In: HALL, Rodney Bruce; BIERSTECKER, Thomas J. (Eds.). The emergence of private authority in global governance. Cambridge: Cambridge University Press, 2002. P. 3-22.

HAUGAARD, Mark. The constitution of power: a theoretical analysis of power, knowledge and structure. Manchester: Manchester University Press, 1997. 234 p.

HOBBES, Thomas. Leviathan: or the matter, form and power of a commonwealth ecclesiasticall and civil. Ed. with an introduction by Michael Oakeshott. Oxford: Basil Blackwell, 1957.

KOENIG-ARCHIBUGI, Mathias. Mapping global governance. In: HELD, David;

MCGREW, Anthony (Eds.). Governing globalization: power, authority and global governance. Oxford: Polity, 2002.

OLIVEIRA, Odete M. Relações internacionais, direito e poder - cenários e protagonismos dos atores não estatais. v. I, Ijuí: ed. Unijuí, 2014, 432 p. 
OLSSON, Giovanni. O Poder Político no Espaço Global: O Protagonismo dos Atores Estatais e Não Estatais. In: OLIVEIRA, Odete M. Relações internacionais, direito e poder - cenários e protagonismos dos atores não estatais. v. I, Ijuí: ed. Unijuí, 2014, 432 p.

OLSSON, Giovanni. Poder político e sociedade internacional contemporânea: governança global com e sem governo e seus desafios e possibilidades. Ijuí: Ed. Unijuí, 2007, 552 p.

PARSONS, Talcott. Sociological theory and modern society. New York. The Free Press, 1967. 564p.

PITKIN, Hanna Fenichel. Wittgenstein and Justice: on the significance of Ludwig Wittgenstein for social and political thought. Berkeley: University of California Press, 1972.

ROSENAU, James N. Governance in a new global order. In: HELD, David; MCGREW, Anthony (Eds.). Governing globalization: power, authority and global governance. Oxford: Polity, 2002. P. 70-86.

RUGGIE, John G. Constructing the world polity: essays on international institutionalization. London: Routledge, 1998.

SANTOS, Boaventura de Sousa. O Direito dos Oprimidos. São Paulo: Editora Cortez, 2014.

WEBER, Max. Wirtschaft und Gesellschaft. 5te revidierte Auflage. Tubingen: Tubingen/Mohr, 1980. 